\title{
Neurally adjusted ventilatory assist improves patient-ventilator interaction in infants as compared with conventional ventilation
}

\author{
Alice Bordessoule', Guillaume Emeriaud' ${ }^{1}$ Sylvain Morneau', Philippe Jouvet ${ }^{1}$ and Jennifer Beck ${ }^{2,3}$
}

BACKGROUND: Neurally adjusted ventilatory assist (NAVA) is a mode of ventilation controlled by the electrical activity of the diaphragm (Edi). The aim was to evaluate patient-ventilator interaction in infants during NAVA as compared with conventional ventilation.

METHODS: Infants were successively ventilated with NAVA, pressure control ventilation (PCV), and pressure support ventilation (PSV). Edi and ventilator pressure (Pvent) waveforms were compared and their variability was assessed by coefficients of variation.

RESULTS: Ten patients (mean age $4.3 \pm 2.4 \mathrm{mo}$ and weight $5.9 \pm 2.2 \mathrm{~kg}$ ) were studied. In PCV and PSV, $4 \pm 4.6 \%$ and $6.5 \pm$ $7.7 \%$ of the neural efforts failed to trigger the ventilator. This did not occur during NAVA. Trigger delays were shorter with NAVA as compared with PCV and PSV $(93 \pm 20$ ms vs. $193 \pm$ $87 \mathrm{~ms}$ and $135 \pm 29 \mathrm{~ms})$. During PCV and PSV, the ventilator cycled off before the end of neural inspiration in $12 \pm 13 \%$ and $21 \pm 19 \%$ of the breaths ( $0 \pm 0 \%$ during NAVA). During PCV and PSV, $24 \pm 11 \%$ and $25 \pm 9 \%$ of the neural breath cycle was asynchronous with the ventilator as compared with $11 \pm 3 \%$ with NAVA. A large variability was observed for Edi in all modes, which was transmitted into Pvent during NAVA (coefficient of variation: $24 \pm 8 \%$ ) and not in PCV (coefficient of variation $2 \pm$ $1 \%)$ or PSV $(2 \pm 2 \%)$.

CONCLUSION: NAVA improves patient-ventilator interaction and delivers adequate ventilation with variable pressure in infants.

C onventional modes of mechanical ventilation are clearly limited in their ability to provide synchrony between the patient and the assist delivered, as demonstrated repeatedly in adults $(1,2)$ and more recently in children (3). Patientventilator asynchrony has been associated with poor clinical outcome $(1,2,4)$. Despite the attempt to improve synchrony with "patient-triggered" modes such as pressure control ventilation (PCV) or pressure support ventilation (PSV), 25\% of adult patients show more than $10 \%$ asynchrony with the ventilator $(1,2,5)$. In pediatric patients, synchrony is particularly difficult to achieve because of the small tidal volumes, high respiratory rates, and weak airway flows and pressures. Ironically, during synchronized intermittent mandatory ventilation, more than half of the patient's breathing cycle is spent in asynchrony (3) with the ventilator.

Besides the poor timing between the patient and the ventilator, patient-ventilator asynchrony also includes the inability of the ventilator to respond to patient demand and the natural breath-to-breath variability. Respiratory variability is a sign of a well functioning respiratory system (6). By definition, PCV and PSV deliver fixed levels of assist, thereby offering no possibility to respond to the patient's respiratory demand and variability.

Neurally adjusted ventilatory assist (NAVA) is a mode of mechanical ventilation that delivers assist in time and in proportion to the electrical activity of the diaphragm (Edi) on a breath-by-breath basis (7). Numerous studies have shown that NAVA efficiently unloads the respiratory muscles $(8,9)$ and delivers more synchronous ventilation than PSV (5,9-12). Furthermore, it was shown that ventilator pressures (during NAVA) follow the natural variability in breathing pattern (13-15).

In smaller patients, NAVA improves patient-ventilator synchrony, as shown in a small physiological trial in seven premature infants (16). In the pediatric population, NAVA has been shown to be feasible $(17,18)$ and to be more in phase with the patient's breathing (19). In none of these studies was a specific evaluation performed on the timing differences between the patient and the ventilator on a breath-by-breath basis. The aim of this study was to evaluate patient-ventilator interaction in a pediatric population during NAVA as compared with conventional ventilation.

\section{RESULTS}

Ten infants were included in this study. Patient diagnosis and ventilator settings at time of inclusion are provided in Table 1. The mean $( \pm \mathrm{SD})$ age was $4.3 \pm 2.3 \mathrm{mo}$, and weight was $5.9 \pm 2.2 \mathrm{~kg}$ (Table 1). All patients but one had uncuffed

'Pediatric Intensive Care, Sainte-Justine Hospital, Université de Montréal, Montréal, Quebec, Canada; ${ }^{2}$ Keenan Research Centre, Li Ka Shing Knowledge Institute, St. Michael's Hospital, Toronto, Ontario, Canada; ${ }^{3}$ Department of Pediatrics, University of Toronto, Toronto, Ontario, Canada. Correspondence: Jennifer Beck (beckj@smh.toronto.on.ca, jennifer.beck@rogers.com) 
Table 1. Patient baseline characteristics

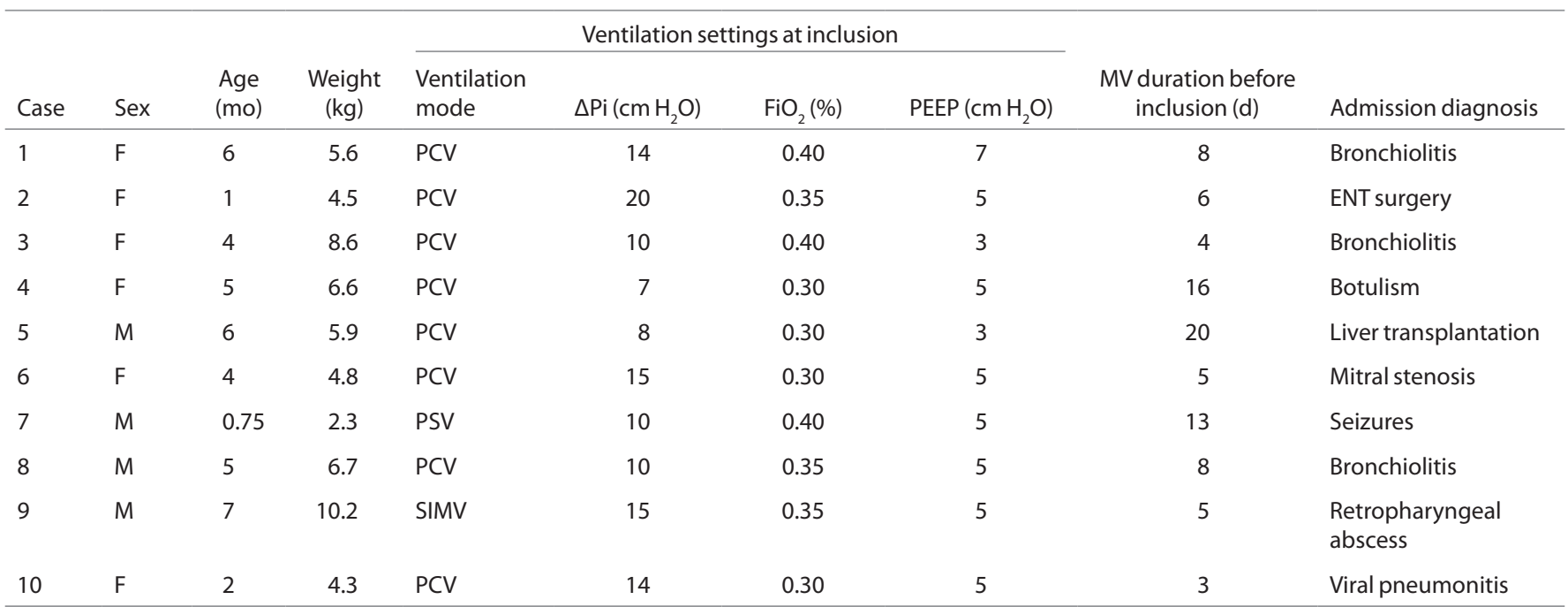

ENT, ear-nose-throat; F, female; $\mathrm{FiO}_{2}$, fraction of inspired oxygen; $\mathrm{M}$, male; $\mathrm{MV}$, mechanical ventilation; PCV, pressure control ventilation; PEEP, positive end-expiratory pressure; PSV, pressure support ventilation; SIMV, synchronized intermittent mandatory ventilation; $\triangle \mathrm{Pi}$, positive inspiratory pressure above PEEP.

endotracheal tubes. Five patients received intermittent doses of fentanyl $(1.3 \pm 0.4 \mathrm{mcg} / \mathrm{kg}, 3 \pm 1$ times during the recording period), of morphine (0.08 $\pm 0.03 \mathrm{mg} / \mathrm{kg}, 2 \pm 1$ times), or of lorazepam $(0.1 \mathrm{mg} / \mathrm{kg}, 1$ time $)$.

\section{Nasogastric Tube Positioning}

In all patients, the initial positioning of the NAVA catheter using the manufacturer's guidelines was close to the final positioning checked by the "NAVA catheter positioning" window on the ventilator. The mean difference between predicted insertion distance and actual insertion with correct positioning was $-0.51 \mathrm{~cm}$ (range $-4-2.3 \mathrm{~cm}$ ). The chest X-ray confirmed that no feeding holes on the catheter were mal-positioned in the esophagus or in the duodenum. During the entire observation period, the Edi catheter needed to be repositioned on two occasions, the catheter being pushed by $0.5 \mathrm{~cm}$ in patient 11 and $2 \mathrm{~cm}$ in patient 9. The first repositioning was systematic to keep the initial position without changes in signal quality; the second was consecutive to a displacement with a loss of signal after an agitation period.

\section{Ventilation and Edi Parameters}

The ventilator and patient parameters are reported in Table 2. The NAVA level at the time of recordings was $1.6 \pm 1.6$ (range $0.4-5.5) \mathrm{cm} \mathrm{H} 2 \mathrm{O} / \mu \mathrm{V}$. There were no significant differences in oxygen saturation $\left(\mathrm{SpO}_{2}\right)$, end tidal $\mathrm{PCO}_{2}$, heart rate, positive end-expiratory pressure (PEEP), fraction of inspired oxygen, tidal volume, or mean and peak ventilator pressure (Pvent) among NAVA, PCV, and PSV (see Table 2).

\section{Patient-Ventilator Interaction}

A mean of $184 \pm 29$ breaths were analyzed in each mode without any difference between the modes. Patient-ventilator interaction was much improved by NAVA, as indicated by shorter trigger delays, a lower accumulated asynchrony index, and a lower percentage of wasted efforts as compared with PCV and PSV (Table 3). For each mode, when the group mean trigger delays were expressed as a percentage of the mean neural inspiratory time, this "relative" trigger delay was lowest with NAVA (15\%), as compared with PCV (25\%) and PSV (23\%). This means that approximately one-quarter of the infant's neural inspiratory time was spent trying to trigger the ventilator during PCV and PSV.

During PCV and PSV, the ventilator cycling-off could occur prematurely or could cycle off late. As illustrated in Figure 1, this resulted in a wide distribution of cycling-off delays in both PCV and PSV, with large inter- and intra-individual variations. The percentage of the breaths where the ventilator cycled off before the peak Edi was highest for PSV (21\% of all breaths, $12 \%$ of the breaths during PCV). In contrast, premature cycling-off was rare in NAVA $(0.3 \pm 0.4 \%)$. When the entire neural breath cycle was considered, the infants were breathing asynchronously with the ventilator during PCV and PSV for $24 \pm 11 \%$ and $25 \pm 9 \%$ of the time, respectively (Figure 2). During NAVA, the asynchrony index was $11 \pm 3 \%$.

The correlation between Edi and Pvent was higher during NAVA than during PCV and PSV $(P<0.01)$. Figure 3 illustrates Edi vs. Pvent in one infant, and shows how during NAVA, the greater the neural inspiratory effort, the larger the Pvent delivered on inspiration. Note that the pressure is limited at very high Edi values (for safety purposes).

\section{Respiratory Variability}

The coefficient of variation showed a large variability in the Edi and was similar in all three modes (Table 3). This variability was only translated into Pvent variability with NAVA (Table 3 , and Figure 4 in one infant), whereas it (Pvent variability) is almost absent in PCV and PSV.

\section{NAVA 5-h Ventilation Period}

All patients tolerated the $5 \mathrm{~h}$ of NAVA ventilation, and no interruption of NAVA was required. There were no significant changes in heart rate, $\mathrm{SpO}_{2}$, or fraction of inspired oxygen for the 5-h period (Table 4). 


\section{Articles | Bordessoule et al.}

Table 2. Patients clinical and ventilatory characteristics during the three study periods

\begin{tabular}{|c|c|c|c|c|}
\hline & NAVA & PCV & PSV & $P$ value ${ }^{a}$ \\
\hline \multicolumn{5}{|l|}{ Ventilation parameters } \\
\hline Delta inspiratory Pvent $\left(\mathrm{cm} \mathrm{H}_{2} \mathrm{O}\right)$ & $12.5(4.4)$ & $11.9(2.7)$ & $12.7(2.3)$ & NS \\
\hline Mean Pvent $\left(\mathrm{cm} \mathrm{H}_{2} \mathrm{O}\right)$ & $7.7(3)$ & $9.3(2)$ & $9.5(3)$ & NS \\
\hline Tidal volume (ml/kg) & $8.7(2.0)$ & $8.4(2.4)$ & $9.1(2.9)$ & NS \\
\hline Edi peak $(\mu \mathrm{V})$ & $10.8(8.3)$ & $8.2(7)$ & $9.5(8.9)$ & NS \\
\hline $\operatorname{Edi} \min (\mu \mathrm{V})$ & $1.2(0.7)$ & $0.9(0.5)$ & $1.6(1.3)$ & NS \\
\hline Neural respiratory rate (bpm) & $46(10)$ & $39(7)$ & $52(17)$ & $P<0.01-P C V$ vs. PSV and PCV vs. NAVA \\
\hline Neural inspiratory time (ms) & $446(122)$ & $547(93)$ & 447 (104) & $P<0.05-P C V$ vs. PSV and PCV vs. NAVA \\
\hline Neural expiratory time (ms) & $1062(250)$ & $1,129(294)$ & $954(313)$ & $P<0.05-P C V$ vs. PSV \\
\hline $\mathrm{ETPCO}_{2}(\mathrm{~mm} \mathrm{Hg})$ & $37(7)$ & $37(8)$ & $37(7)$ & NS \\
\hline
\end{tabular}

Means (SD) are presented.

bpm, breaths per minute; Edi, electrical activity of diaphragm; ETPCO $2^{\prime}$ end tidal $\mathrm{PCO}_{2}$; $\mathrm{NAVA}$, neurally adjusted ventilatory assist; NS, no significance; PCV, pressure control ventilation; PSV, pressure support ventilation; Pvent, airway pressure; $\mathrm{SpO}_{2^{\prime}}$ oxygen saturation.

ane-way repeated-measure ANOVA P values are reported, with significant between-group differences (Student-Newman-Keuls test).

Table 3. Patient-ventilator interaction and respiratory variability

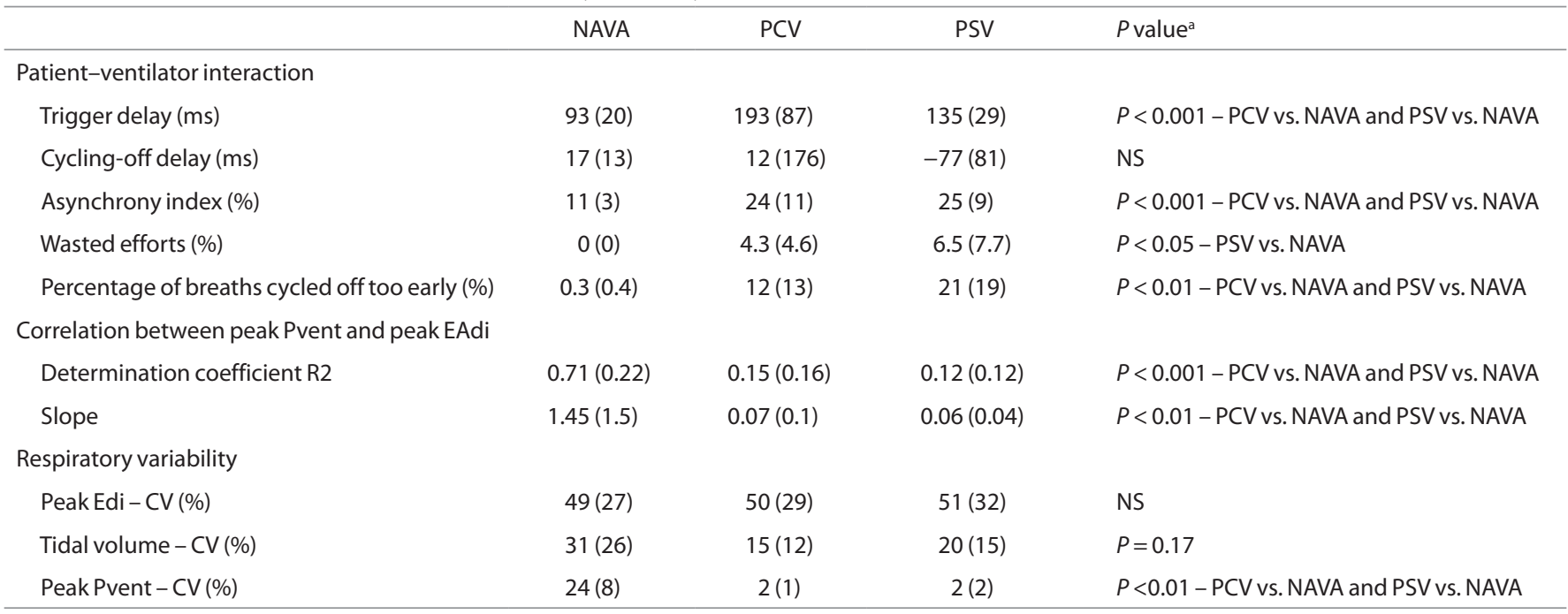

Means (SD) are presented.

CV, coefficient of variation; Edi, electrical activity of diaphragm; NAVA, neurally adjusted ventilatory assist; NS, no significance; PCV, pressure control ventilation; PSV, pressure support ventilation; Pvent, airway pressure.

ane-way repeated-measure ANOVA P values are reported, with significant differences between groups (Student-Newman-Keuls test).

\section{DISCUSSION}

This study confirms previous reports that conventional ventilation is inadequate in providing patient-ventilator synchrony. In this group of patients, NAVA significantly reduced the number of wasted inspiratory efforts and reduced trigger delays and cycling-off delays, leading to an overall lower accumulated asynchrony index. Besides the improved timing, ventilation with NAVA allowed the translation of the large natural variability of the ventilatory drive into pressure variability. Despite the high variability in neural breathing pattern during PCV and PSV, these conventional modes with fixed levels of assist do not allow pressure variability.

\section{Patient-Ventilator Interaction}

In these mechanically ventilated infants, NAVA improved the detection of neural inspiration by the ventilator, as illustrated by the reduced trigger delay and the lack of wasted efforts as compared with the conventional modes. This resulted in a 


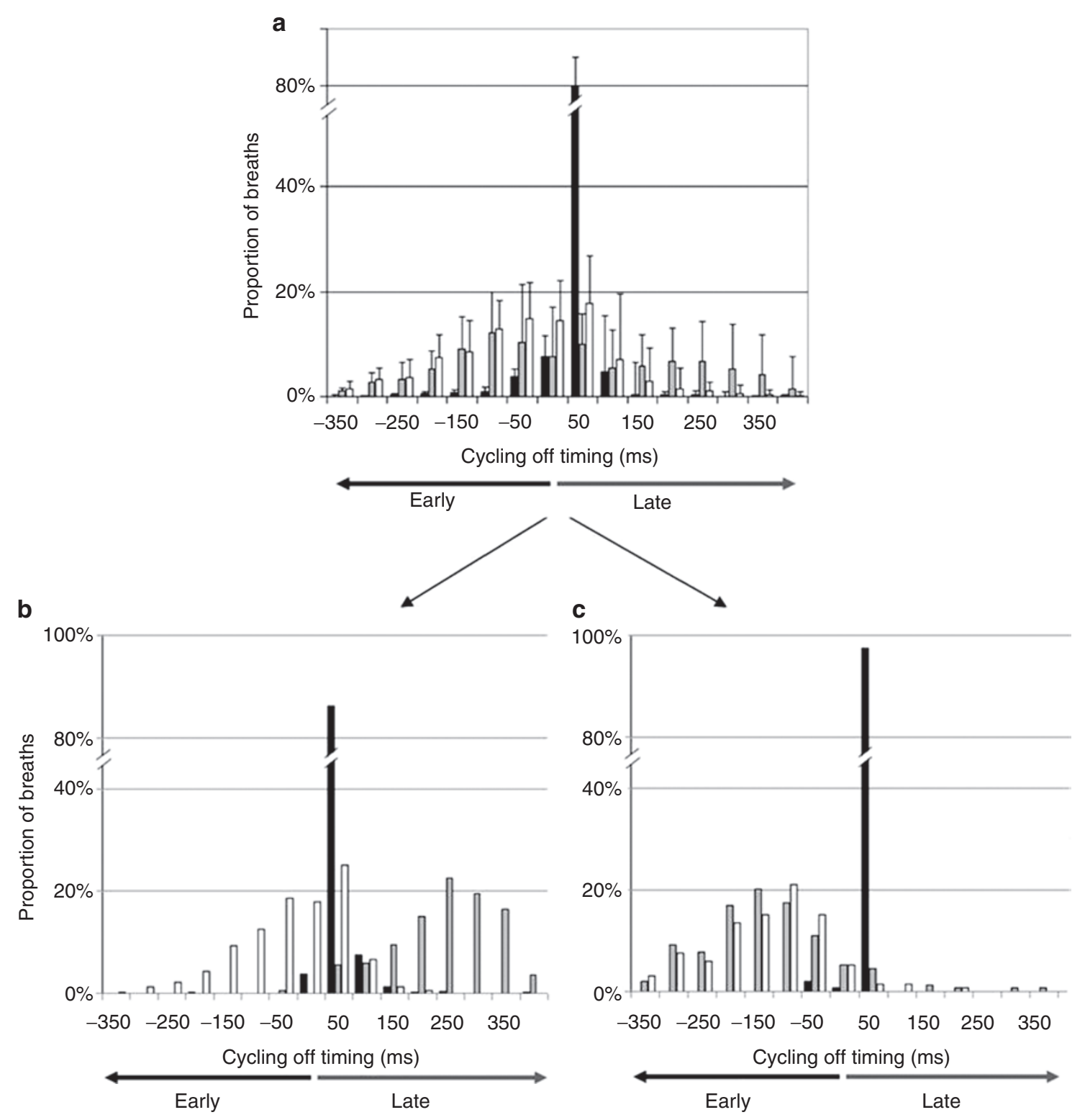

Figure 1. Distribution of cycling-off delays for all three modes. (a) Histogram displaying proportion of breaths ( $y$ axis) with different cycling-off delays ( $x$ axis) for the group, for neurally adjusted ventilatory assist (NAVA) (black), pressure control ventilation (PCV) (gray), and pressure support ventilation (PSV) (white). During NAVA nearly $80 \%$ of the breaths cycled off with minimal delays (bar is close to $0 \mathrm{~ms}$ ). However, in PCV and PSV, there was a much wider distribution of cycling-off delays. (b and c) In some patients, the ventilator cycling off is predominantly delayed (positive values, example patient 1; b), whereas in others premature cycling off predominates (negative cycling-off delay, example patient $7 ; \mathbf{c}$ ).

decreased asynchrony index during NAVA by more than $50 \%$ (from $\sim 25 \%$ in conventional modes to $11 \%$ during NAVA). These results are in line with studies in adults that all reported similar synchrony improvement with NAVA $(5,11,12,20,21)$. In the pediatric population, no study has yet quantified the trigger delays and cycling-off delays during conventional ventilation and during NAVA, although two feasibility studies have demonstrated that during NAVA, at least two-thirds of assisted breaths were triggered by the neural signal $(17,18)$. A recent study in a heterogeneous pediatric population showed, similar to our findings, that the inspiratory and expiratory phases of the ventilator match the neural phases of the patient better during NAVA ( $91 \%$ of the time was synchronous) as compared with PCV or pressure-regulated volume-control mode (66\% of the time was synchronous) (19).

We also observed very short cycling-off delays with NAVA, but paradoxically, the average value was not significantly different from PCV and PSV. By plotting the distribution (histogram) of the cycling-off timing differences, it became clear that the small average value was because of the averaging of large negative (too early) and positive (too late) cycling-off delays. As illustrated in Figure 1, during PCV and PSV, both delayed and premature cycling-off occurred frequently, unlike in NAVA. Optimization of cycling off in children less than $1 \mathrm{y}$ old is particularly important considering their strong Hering-Breuer reflexes. The Hering-Breuer 


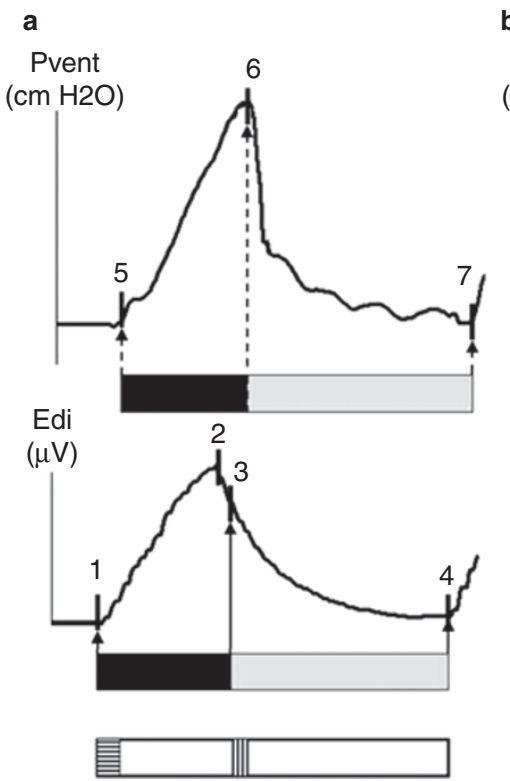

b (cm H2O)

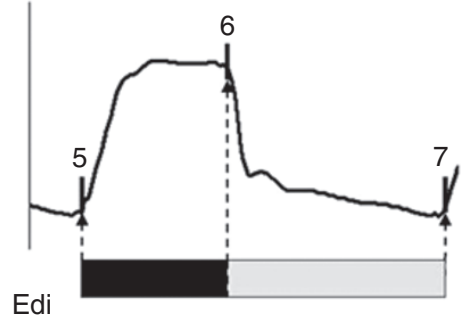

$(\mu \mathrm{V})$

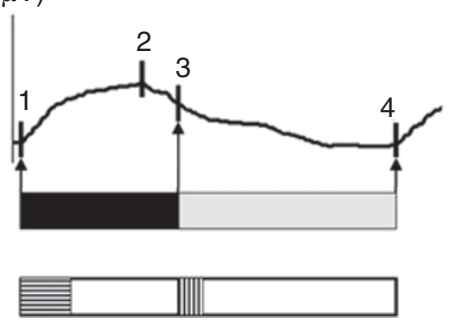

C

Pvent (cm H2O)

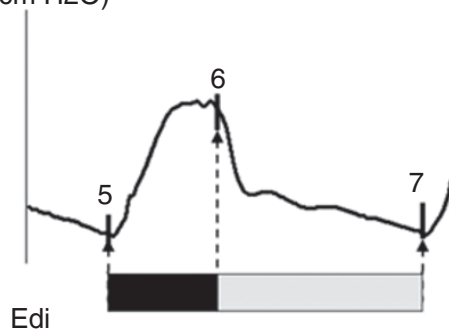

$(\mu \mathrm{V})$

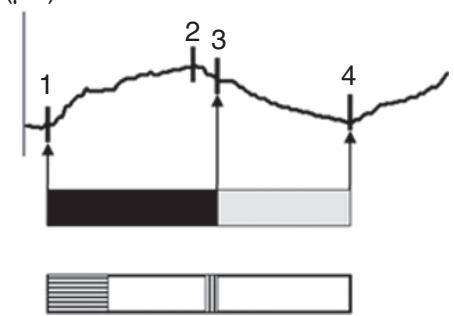

Figure 2. Examples of ventilator pressure and electrical activity of the diaphragm for one breath during neurally adjusted ventilatory assist (NAVA), pressure control ventilation (PCV), and pressure support ventilation (PSV). During (a) NAVA, (b) PCV, and (c) PSV, tracings of ventilator pressure (Pvent) and electrical activity of diaphragm (Edi) are shown for one breath, illustrating the position of the seven cursors placed during the analysis of the timings (labeled 1-7): (1) beginning of Edi increase, (2) peak of Edi, (3) 70\% of peak Edi, (4) beginning of subsequent Edi increase, (5) beginning of Pvent increase, (6) end of Pvent (i.e., ventilator cycling off), (7) beginning of subsequent Pvent increase. Top tracings: Pvent waveform and determination of assist period (black horizontal bars) and period for positive end-expiratory pressure (gray horizontal bars). Lower tracings: Edi waveform and definition of neural inspiratory portion to $70 \%$ of peak Edi (black horizontal bars), as well as neural expiration (gray horizontal bars). The trigger (horizontal hatched) and cycling-off (vertical hatched) delays are presented (asynchronous period). The period in synchrony is displayed in white.
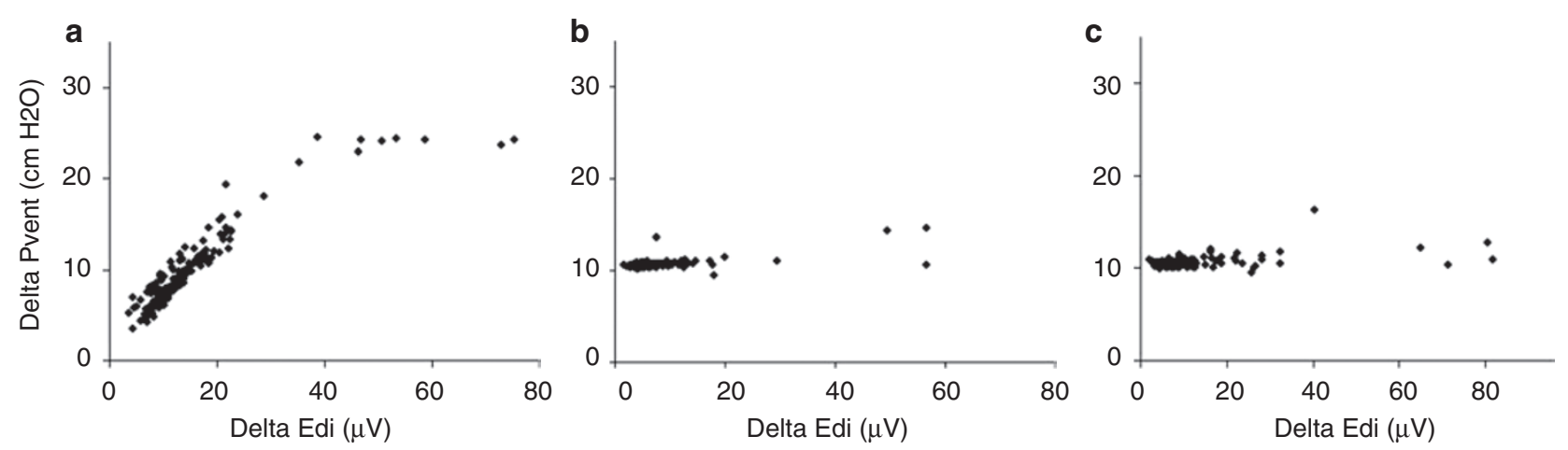

Figure 3. Relationship between ventilator pressure and diaphragm activity in one infant for all three modes. Delta ventilator pressure (Delta Pvent, $y$ axis) and delta electrical activity of the diaphragm (Delta Edi, $x$ axis) are plotted in one subject for (a) neurally adjusted ventilatory assist (NAVA), (b) pressure control ventilation (PCV), and (c) pressure support ventilation (PSV). Delta Pvent (calculated as Peak Pvent - positive end-expiratory pressure) and delta Edi (calculated as Edi peak - Edi min) are highly correlated in NAVA, except for the highest Edi values where the Pvent was limited by upper pressure safety limits. No relation between delta Pvent and delta Edi was observed in PCV or PSV.

inflation-sensitive reflex is modulated by stretch receptors in the lung. During inspiration, at a critical inspired volume, this vagally mediated reflex feeds back to the respiratory centers to terminate inspiration. When inspiration terminates, the Edi waveform begins to decline, and during NAVA, this signals the ventilator to cycle off the breath. During PSV, even if the critical volume has been reached and Edi begins to decline, the assist may continue until the cycling-off criteria have been reached. The elevated and prolonged volume-via this reflex-promotes a prolongation in expiratory time (3). This in turn results in a reduced respiratory rate (3).
Prolonged delivery of assist has previously been described in this population during time-cycled breaths (3). In our study, the cycling-off criteria were based on a fixed inspiratory time during PCV ( $0.5 \mathrm{~s}$ in this study, as compared with $0.7 \mathrm{~s}$ in Beck et al.'s (3) study), and set at $25 \%$ of the peak inspiratory flow during PSV. Different settings could have resulted in different mean cycling-off delays. However, the dispersion of delays in PCV and PSV reflects that the cycling off is dependent on conditions that are varying cycle by cycle. These varying parameters include patient inspiratory effort, neural inspiratory and expiratory time, the level of assist, the time constant of the 
a
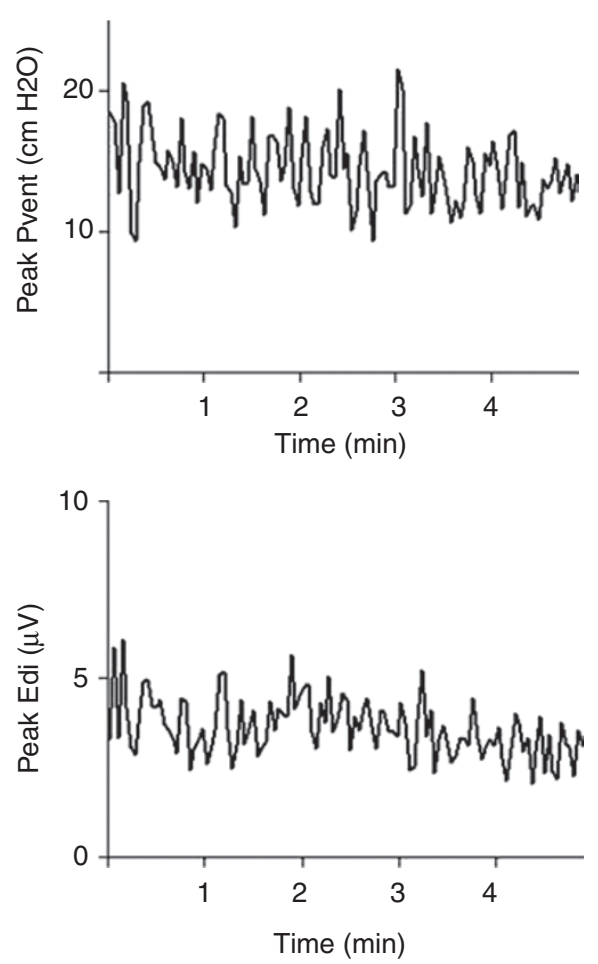

b
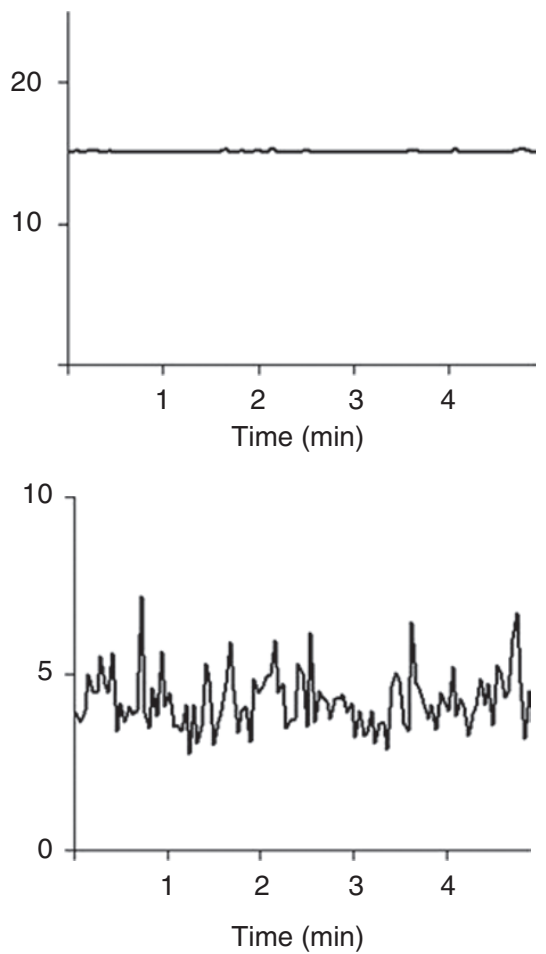

C
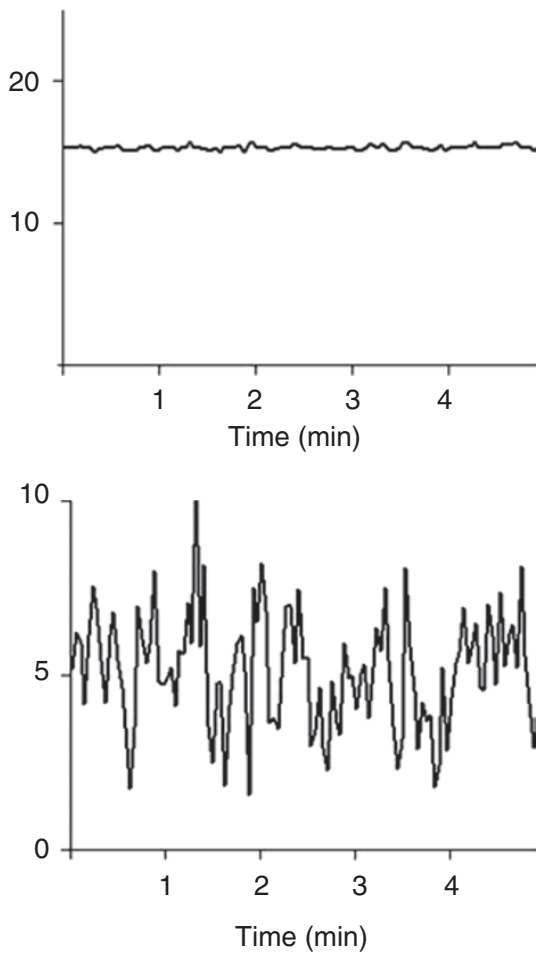

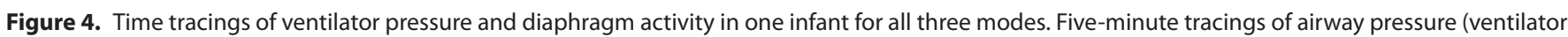
pressure (Pvent), upper panels) and electrical activity of diaphragm (Edi, lower panels) in one representative patient during (a) NAVA, (b) PCV, and (c) PSV, illustrating the similar pattern of Edi variability in the three modes, whereas Pvent variability is observed only with NAVA.

Table 4. Evolution of clinical parameters during the 5-h NAVA period

\begin{tabular}{lcccccrr}
\hline & $\mathrm{H} 0$ & $\mathrm{H} 1$ & $\mathrm{H} 2$ & $\mathrm{H} 3$ & $\mathrm{H} 4$ & $\mathrm{H} 5$ & $P$ value \\
\hline Heart rate & $133 \pm 20$ & $130 \pm 22$ & $135 \pm 16$ & $133 \pm 14$ & $127 \pm 11$ & $133 \pm 7$ & 0.53 \\
Respiratory rate & $46 \pm 12$ & $47 \pm 16$ & $43 \pm 11$ & $50 \pm 14$ & $44 \pm 12$ & $54 \pm 7$ & 0.67 \\
End tidal CO & $36 \pm 7$ & $36 \pm 7$ & $37 \pm 6$ & $37 \pm 7$ & $37 \pm 9$ & $44 \pm 7$ & 0.76 \\
$\mathrm{SpO}_{2}$ & $99 \pm 2$ & $99 \pm 2$ & $100 \pm 0$ & $99 \pm 1$ & $99 \pm 1$ & $100 \pm 1$ & 0.65 \\
$\mathrm{FiO}_{2}$ & $34 \pm 6$ & $33 \pm 5$ & $34 \pm 6$ & $32 \pm 5$ & $32 \pm 4$ & $30 \pm 0$ \\
$\mathrm{PEEP}$ & $5 \pm 1$ & $5 \pm 1$ & $5 \pm 1$ & $5 \pm 1$ & $5 \pm 1$ & $5 \pm 1$ & 0.09 \\
\hline
\end{tabular}

$\mathrm{FlO}_{2}$, fraction of inspired oxygen; $\mathrm{H}$, hour; $\mathrm{PEEP}$, positive end-expiratory pressure; $\mathrm{SpO}_{2^{\prime}}$ oxygen saturation.

ane-way repeated-measure ANOVA $P$ values are reported.

respiratory system, and the level of end-expiratory lung volume $(22,23)$.

Up to one-fifth of the breaths during conventional ventilation showed cycling off before the peak of the Edi. In effect, this means that the exhalation valve was opened, allowing expiration and hence diaphragm lengthening. This was occurring as the diaphragm was still activated and neural inspiration was continuing. This situation could possibly be interpreted as an eccentric contraction of the diaphragm, which could potentially lead to structural damage of the diaphragm and a rapid decline in force, as reported in an animal model (24).

Besides the temporal dimension of synchrony, we also observed an improved correlation between the Edi and Pvent with NAVA. This proportionality is inherent to the NAVA principle and is therefore not surprising. This amplitude dimension of synchrony has already been reported in premature infants (16) and in adults (5) and reflects the concept of respiratory muscle unloading. In the case of increased diaphragm activation, NAVA delivers an increased ventilatory support on the basis of the assumption that one crucial goal of mechanical ventilation is to unload the ventilatory efforts toward recovering. In contrast, conventional modes do not respond to this increased diaphragm activation and deliver a constant support or even a reduced assist (25).

During NAVA, an upper pressure limit is required as a safety measure to prevent lung overdistension, in the case of large intermittent Edi values. Therefore, in this study, the proportionality between Edi and Pvent during NAVA was intentionally limited at the upper pressure limit. During the NAVA arm in this study, the upper pressure limit was clinically determined 
for each patient, and the functionality of the mode is such that pressure is actually limited $5 \mathrm{~cm} \mathrm{H}_{2} \mathrm{O}$ below the dialed-in value. High levels of Edi intermittently occur in infants, during periods of agitation or sighs, and could generate temporary high Pvent during NAVA. On the one hand, such high pressures could favor lung recruitment (recruitment maneuvers are sometimes prescribed in conventional ventilation), but on the other hand, they may also expose a risk of overdistension. As the evidence concerning the benefits of these high, intermittent pressures is controversial, we judged it more cautious to prevent these very high pressure occurrences with the use of the upper pressure limit.

In studies comparing conventional ventilation to NAVA (and in those studies where the NAVA level was adjusted so that peak pressures were matched), most have reported lower mean airway pressure during NAVA $(16,17,19,26)$. In our study, a trend for lower mean airway pressure was also observed, but it did not reach significance $(P=0.17)$, probably because of insufficient power (retrospectively calculated power at 28\%).

\section{Respiratory Variability}

Breath-to-breath variability is a normal characteristic of ventilation that reflects the degree of freedom-and therefore the adaptability - of the ventilatory control system $(6,27,28)$. A decreased variability is associated with respiratory disease in adults (29) and in infants (22), and a lower variability is a predictor of weaning failure (30). In this study, the patients exhibited a large variability of their ventilatory drive whatever the mode, as reflected by large coefficient of variation of peak Edi. In contrast, this variability was translated into pressure variability only with NAVA. Similar results have been reported in adults $(5,15,20)$. Theoretical data suggest that pressure variability allows the optimization of lung recruitment with lower ventilatory pressure (31), which has been confirmed in animal models (32).

\section{Critique of Methods}

This study could be criticized for implementing NAVA longer (5h) than PCV (30 min) and PSV (30 min), and for analyzing only $5 \mathrm{~min}$ at the end of each run. The main hypothesis of this work was that NAVA - similar to previous physiological studies in adults $(12,20)$ and preterm infants (16) - would improve patient-ventilator interaction. In those previous studies, $5 \mathrm{~min}$ of data analysis was sufficient to detect improvements in patient-ventilator interaction. In our data pool, an average of 184 breaths were analyzed in each mode, which would in theory be twice the number of breaths analyzed in adults (whose respiratory rate is roughly half that of an infant).

We believe that our small sample size of 10 infants was adequate to demonstrate that the Edi was a suitable signal to control the ventilator and improve synchrony. Ten of 10 infants demonstrated proportionality and synchrony when ventilated with NAVA. The authors find that this sample size, although relatively small, is sufficient for a study that was designed to compare patient-ventilator synchrony in different modes of ventilation. We do admit that this group size does not permit evaluation of important clinical outcomes and future studies are warranted to assess them.

Regarding the duration of NAVA vs. the duration of PCV and PSV, in this study, we first implemented NAVA for $5 \mathrm{~h}$ to observe feasibility and tolerance to this new mode. At the initial planning stages of this study, very little was known about how NAVA performs in infants, especially under routine clinical interventions. Our results indicated clinical stability over the 5 -h period. We do not believe that $5 \mathrm{~h}$ of NAVA ventilation before delivering PCV and PSV for $30 \mathrm{~min}$ each would influence the results for patient-ventilator interaction, which was the main outcome of the present work. According to Viale et al. (33) it takes approximately six to eight breaths for patients to adapt their breathing pattern to an adjustment in ventilator assist.

The authors acknowledge that the magnitude of improved synchrony will of course depend on the disease etiology, the settings in the conventional ventilation arm (PCV and PSV in this study), and the indexes used to quantify the improvement. It is known that patients requiring higher assist levels have worsened patient-ventilator interaction during conventional ventilation $(1,4)$. Of note is that PCV and PSV settings were based on clinical decisions, without the use of the Edi signal as feedback. If the Edi signal had been used as a monitoring tool to adjust ventilator settings in PCV and PSV, the synchrony during these modes perhaps could be have been optimized. Optimization of patient-ventilator interaction with feedback about the Edi during conventional modes proposes to be an interesting concept for future studies.

During the study period, NAVA was well tolerated and was never interrupted even after intermittent sedation administrations. By the nature of the eligibility criteria for this study, the patients were not receiving high doses of sedation. Further studies are warranted to evaluate the impact of deeper sedation on NAVA feasibility.

The authors highlight the fact that this pediatric intensive care unit, with extensive clinical and research experience in conventional modes of ventilation, had no routine clinical experience with NAVA. The Servoi ventilator (for providing NAVA, PCV, and PSV) was introduced especially for this study, and the improvements in synchrony therefore could not have been due to experience with NAVA per se.

In conclusion, this study confirms the feasibility of NAVA in critically ill infants. NAVA significantly improves infant-ventilator synchrony, in both temporal and amplitude dimensions, and permits the transmission of the spontaneous variability into ventilatory pressure.

\section{METHODS}

The protocol was approved by the ethical and scientific committees of Sainte-Justine Hospital, Montreal, Quebec, Canada (protocol \#2537). Written informed consent was obtained from the parents or guardian.

\section{Subjects}

Patients were eligible if they were $<1 \mathrm{y}$, intubated and mechanically ventilated, and breathing spontaneously (i.e., ability to trigger the ventilator), and had a plateau pressure $\leq 22 \mathrm{~cm} \mathrm{H}_{2} \mathrm{O}$ above the PEEP and a PEEP $\leq 7 \mathrm{~cm} \mathrm{H}_{2} \mathrm{O}$. 
The exclusion criteria were pneumothorax on chest X-ray, degenerative neuromuscular disease, bleeding disorders, vasoactive drug infusion (dopamine $\geq 5 \mu \mathrm{g} / \mathrm{kg} / \mathrm{min}$ or any dose of epinephrine, norepinephrine, dobutamine, or vasopressin), cyanotic congenital cardiovascular disease, diagnosed phrenic nerve damage, esophageal perforation, use of high-frequency oscillatory or jet ventilation, contraindication to change nasogastric tube, parent refusal, or patient declared too unstable by the attending physician.

\section{Measurements}

Edi was measured with a naso/orogastric feeding tube, with miniaturized electrodes placed at its distal end (size 8F NAVA catheter, Maquet, Solna, Sweden). Note that the Edi is the same measurement as EAdi used in previous publications $(3,7-9,12,16)$. Edi, as well as Pvent were acquired from the ventilator on a laptop (NAVA tracker, Maquet; software version 2.0) and stored for later analysis. $\mathrm{SpO}_{2}$, end tidal $\mathrm{PCO}_{2}$, heart rate, fraction of inspired oxygen, and catheter positioning were recorded every hour.

\section{General Principles of NAVA}

During NAVA, the pressure delivery is controlled by the Edi waveform, processed according to standardized algorithms (34). The Edi signal is used to trigger on and cycle off the assist. The Edi is also the controller signal for the amount of pressure delivered during inspiration and is multiplied by a proportionality factor known as the NAVA level to adjust the level of assist (7). In this study, NAVA and the conventional modes were delivered by a Servo ${ }^{i}$ ventilator (Maquet; version v4.0). As a safety feature, an upper pressure limit can be dialed in. During NAVA, the pressure is limited at a pressure $5 \mathrm{~cm} \mathrm{H}_{2} \mathrm{O}$ below this upper limit.

\section{Protocol}

After obtaining informed consent, the patient's nasogastric feeding tube was replaced with the Edi catheter. The following day, the conventional respirator was switched to the Servo. The clinically prescribed settings were kept the same. Correct positioning of the Edi catheter was then verified with the "NAVA catheter positioning" window on the Servo. As the experience with Edi catheter positioning was limited in our unit, a chest X-ray was also obtained to confirm the feeding holes' position. A chest X-ray is not typically needed to confirm correct placement of the catheter and so was undertaken by the investigators for this specific study.

Initially, Edi was monitored during conventional ventilation for 30 min, during which time preparations were made to set the NAVA level. The NAVA level was adjusted to match the current and prescribed peak pressure for the subsequent NAVA period. After adjustment of the NAVA level, the ventilation mode was switched to NAVA for $5 \mathrm{~h}$. This 5 -h period of NAVA ventilation was undertaken to evaluate tolerance and clinical stability, as very few reports had been published about the use of NAVA for several hours in pediatric patients. The trigger level was set at $0.5 \mu \mathrm{V}$ (default value). During NAVA, the cycling-off criteria were fixed at $70 \%$ of the peak Edi. The upper pressure limit on the ventilator was set according to the safety limits routinely used in the pediatric intensive care unit at this institution.

At the end of the NAVA period, infants were successively ventilated for $30 \mathrm{~min}$ in PCV and $30 \mathrm{~min}$ in PSV with the initial, clinically prescribed PEEP and support level (i.e., both PCV and PSV were set clinically without feedback from the Edi).

In PCV, inspiratory time was also set clinically (average $0.53 \mathrm{~s}$, range $0.5-0.6$ ) with a backup rate of $13 \pm 1 / \mathrm{min}$. In PSV, the trigger was set at $0.25 \mathrm{l} / \mathrm{min}$, and the cycling-off criterion was $25 \%$ of the peak flow (default settings). The backup rate during PSV (in case of apnea) was set at $20 \pm 0 / \mathrm{min}$. Throughout the study, the leak compensation algorithm was activated. The rise time used was the default value $(0.15 \mathrm{~s})$.

The total duration of the experimental protocol was $6.5 \mathrm{~h}$ in each infant (30 min monitoring initially with clinical mode and settings + $5 \mathrm{~h}$ of NAVA $+30 \mathrm{~min}$ PCV +30 min PSV).

\section{Data Analysis}

Patient-ventilator interaction. As previously described (9) a breathby-breath analysis was used to compare ventilator and neural timings for the three modes, for each triggered breath. The last $5 \mathrm{~min}$ of each ventilator period was analyzed. This period of analysis has been shown to be sufficient for analyzing patient-ventilator interaction in both adults (5) and premature infants (16) With a visual and simultaneous display of Edi and Pvent, seven time cursors were manually placed (see Figure 2). From the Pvent waveform, we calculated the period of assist (ventilator inspiratory time) and ventilator expiratory time. From cursors placed on the Edi signal, we calculated neural inspiratory time (difference in time between beginning and peak of Edi), neural expiratory time (difference in time from the peak of Edi to the beginning of the subsequent Edi increase). The neural total breath cycle was the sum of neural inspiratory and neural expiratory times.

The trigger delay was calculated as the time between the onset of Pvent minus the onset of Edi, and has the units of milliseconds (ms). To put this number into physiological relevance, the trigger delays (in $\mathrm{ms}$ ) were also divided by neural inspiratory time (in ms). Expressed as a ratio, this takes into account any changes in neural breathing pattern when switching modes.

The cycling-off delay was calculated as the time between the end of Pvent minus the time at $70 \%$ of the peak Edi and has the units of ms. Note that trigger and cycling-off delays can be positive (i.e., the ventilator is late as compared with Edi) or negative (i.e., the ventilator stops prematurely as compared with Edi).

The number of breaths with "premature cycling off" was counted and expressed as a percentage of the neural respiratory rate and was defined as cycling off of the assist before peak Edi.

An accumulated asynchrony index was calculated as previously described $(12,35)$ : Asynchrony index $(\%)=($ trigger delay + cyclingoff delay) $/$ (neural total breath cycle) $\times 100$. This index represents the proportion of the breath cycle where neural activity and ventilator assist do not match (Figure 2).

Wasted inspiratory efforts, identified as inspiratory deflections in Edi that failed to trigger the ventilator, were counted and expressed as percentage of the total number of neural inspiratory efforts (12).

To evaluate the relationship and proportionality between ventilator assist and patient respiratory demand, we performed linear regression analysis on the inspiratory Edi (Edi peak - Edi min) and the inspiratory Pvent (delta pressure above PEEP) for each breath in each patient for each mode. During NAVA, the pressure-limited breaths were excluded from this analysis. A correlation coefficient between Edi and Pvent was calculated, as well as the slope of the regression line, as previously described $(5,16)$.

Respiratory variability. The coefficient of variation was calculated (SD divided by the mean multiplied by 100) to evaluate the variability of Edi, tidal volume, and Pvent $(36,37)$.

\section{Statistical Analysis}

Statistical analysis was performed with commercially available software (SPSS statistics 17, Chicago, IL). Data are presented as mean \pm SD. Repeated-measures ANOVA was used to compare variables in the three conditions (NAVA, PSV, and PCV), and post hoc analysis between groups was tested with a Student-Newman-Keuls test. The hourly data of heart rate, $\mathrm{SpO}_{2}$, end tidal $\mathrm{CO}_{2}$, and fraction of inspired oxygen was analyzed with repeated measures ANOVA. A $P$ value < 0.05 was considered to be significant.

\section{ADDITIONAL AUTHOR INFORMATION}

Literature search was done by J.B., A.B., and P.J.; study design was done by J.B. and P.J.; data collection was done by A.B., P.J., and S.M.; data analysis was done by J.B., G.E., and A.B.; data interpretation was done by J.B. and G.E.; and writing was done by A.B., J.B., G.E., and P.J.

\section{ACKNOWLEDGMENTS}

The study was performed at the Pediatric Intensive Care Unit of Hôpital SteJustine, Montreal, Canada. The authors thank M. Norman Comtois for his help with the data analysis.

\section{STATEMENT OF FINANCIAL SUPPORT}

This study was supported by a grant provided by the "Societé de Réanimation de Langue Française." Maquet Critical Care provided the ventilator and catheters for this study. 
Disclosure: J.B. has made inventions related to neural control of mechanical ventilation that are patented. The license for these patents belongs to Maquet Critical Care. Future commercial uses of this technology may provide financial benefit to J.B. through royalties. J.B. owns $50 \%$ of Neurovent Research Inc. (NVR). NVR is a research and development company that builds the equipment and catheters for research studies. NVR has a consulting agreement with Maquet Critical Care. A.B., G.E., S.M., and P.J. have nothing to declare.

\section{REFERENCES}

1. Thille AW, Rodriguez P, Cabello B, Lellouche F, Brochard L. Patient-ventilator asynchrony during assisted mechanical ventilation. Intensive Care Med 2006;32:1515-22.

2. de Wit M, Pedram S, Best AM, Epstein SK. Observational study of patient-ventilator asynchrony and relationship to sedation level. J Crit Care 2009;24:74-80.

3. Beck J, Tucci M, Emeriaud G, Lacroix J, Sinderby C. Prolonged neural expiratory time induced by mechanical ventilation in infants. Pediatr Res 2004;55:747-54.

4. Rozé H, Lafrikh A, Perrier V, et al. Daily titration of neurally adjusted ventilatory assist using the diaphragm electrical activity. Intensive Care Med 2011;37:1087-94.

5. Colombo D, Cammarota G, Bergamaschi V, De Lucia M, Corte FD, Navalesi P. Physiologic response to varying levels of pressure support and neurally adjusted ventilatory assist in patients with acute respiratory failure. Intensive Care Med 2008;34:2010-8.

6. Macklem PT. [A matter of life and death]. Rev Mal Respir 2002;19 (2 Pt1):135-9.

7. Sinderby C, Navalesi P, Beck J, et al. Neural control of mechanical ventilation in respiratory failure. Nat Med 1999;5:1433-6.

8. Allo JC, Beck JC, Brander L, Brunet F, Slutsky AS, Sinderby CA. Influence of neurally adjusted ventilatory assist and positive end-expiratory pressure on breathing pattern in rabbits with acute lung injury. Crit Care Med 2006;34:2997-3004.

9. Beck J, Campoccia F, Allo JC, et al. Improved synchrony and respiratory unloading by neurally adjusted ventilatory assist (NAVA) in lung-injured rabbits. Pediatr Res 2007;61:289-94.

10. Pronovost PJ, Thompson DA, Holzmueller CG, et al. Toward learning from patient safety reporting systems. J Crit Care 2006;21:305-15.

11. Terzi N, Pelieu I, Guittet L, et al. Neurally adjusted ventilatory assist in patients recovering spontaneous breathing after acute respiratory distress syndrome: physiological evaluation. Crit Care Med 2010;38:1830-7.

12. Spahija J, de Marchie M, Albert M, et al. Patient-ventilator interaction during pressure support ventilation and neurally adjusted ventilatory assist. Crit Care Med 2010;38:518-26.

13. Schweickert WD, Pohlman MC, Pohlman AS, et al. Early physical and occupational therapy in mechanically ventilated, critically ill patients: a randomised controlled trial. Lancet 2009;373:1874-82.

14. Coisel Y, Chanques G, Jung B, et al. Neurally adjusted ventilatory assist in critically ill postoperative patients: a crossover randomized study. Anesthesiology 2010;113:925-35.

15. Schmidt M, Demoule A, Cracco C, et al. Neurally adjusted ventilatory assist increases respiratory variability and complexity in acute respiratory failure. Anesthesiology 2010;112:670-81.

16. Beck J, Reilly M, Grasselli G, et al. Patient-ventilator interaction during neurally adjusted ventilatory assist in low birth weight infants. Pediatr Res 2009;65:663-8.

17. Breatnach C, Conlon NP, Stack M, Healy M, O'Hare BP. A prospective crossover comparison of neurally adjusted ventilatory assist and pressure- support ventilation in a pediatric and neonatal intensive care unit population. Pediatr Crit Care Med 2010;11:7-11.

18. Bengtsson JA, Edberg KE. Neurally adjusted ventilatory assist in children: an observational study. Pediatr Crit Care Med 2010;11:253-7.

19. Alander M, Peltoniemi O, Pokka T, Kontiokari T. Comparison of pressure-, flow-, and NAVA-triggering in pediatric and neonatal ventilatory care. Pediatr Pulmonol 2012;47:76-83.

20. Brander L, Leong-Poi H, Beck J, et al. Titration and implementation of neurally adjusted ventilatory assist in critically ill patients. Chest 2009;135:695-703.

21. Piquilloud L, Vignaux L, Bialais E, et al. Neurally adjusted ventilatory assist improves patient-ventilator interaction. Intensive Care Med 2011;37:263-71.

22. Emeriaud G, Baconnier P, Eberhard A, Debillon T, Calabrese P, Benchetrit G. Variability of end-expiratory lung volume in premature infants. Neonatology 2010;98:321-9.

23. Du HL, Amato MB, Yamada Y. Automation of expiratory trigger sensitivity in pressure support ventilation. Respir Care Clin N Am 2001;7:503$17, x$.

24. Gea J, Zhu E, Gáldiz JB, et al. [Functional consequences of eccentric contractions of the diaphragm]. Arch Bronconeumol 2009;45:68-74.

25. Sinderby C, Beck J. Proportional assist ventilation and neurally adjusted ventilatory assist-better approaches to patient ventilator synchrony? Clin Chest Med 2008;29:329-42, vii.

26. Stein $\mathrm{H}$, Howard D. Neurally adjusted ventilatory assist in neonates weighing < 1500 grams: a retrospective analysis. J Pediatr 2012;160:786-789.e1.

27. Benchetrit G. Breathing pattern in humans: diversity and individuality. Respir Physiol 2000;122:123-9.

28. Tobin MJ, Yang KL, Jubran A, Lodato RF. Interrelationship of breath components in neighboring breaths of normal eupneic subjects. Am J Respir Crit Care Med 1995;152(6 Pt 1):1967-76.

29. Brack T, Jubran A, Tobin MJ. Dyspnea and decreased variability of breathing in patients with restrictive lung disease. Am J Respir Crit Care Med 2002;165:1260-4.

30. Wysocki M, Cracco C, Teixeira A, et al. Reduced breathing variability as a predictor of unsuccessful patient separation from mechanical ventilation. Crit Care Med 2006;34:2076-83.

31. Suki B, Alencar AM, Sujeer MK, et al. Life-support system benefits from noise. Nature 1998;393:127-8.

32. Mutch WA, Eschun GM, Kowalski SE, Graham MR, Girling LG, Lefevre GR. Biologically variable ventilation prevents deterioration of gas exchange during prolonged anaesthesia. Br J Anaesth 2000;84:197203.

33. Viale JP, Duperret S, Mahul P, et al. Time course evolution of ventilatory responses to inspiratory unloading in patients. Am J Respir Crit Care Med 1998; 157:428-34.

34. Aldrich TK, Sinderby C, McKenzie DK, Estenne M, Gandevia SC. ATS/ ERS Statement on respiratory muscle testing. Am J Respir Crit Care Med 2002; 166:518-624.

35. Moerer O, Beck J, Brander L, et al. Subject-ventilator synchrony during neural versus pneumatically triggered non-invasive helmet ventilation. Intensive Care Med 2008;34:1615-23.

36. Tobin MJ, Mador MJ, Guenther SM, Lodato RF, Sackner MA. Variability of resting respiratory drive and timing in healthy subjects. J Appl Physiol 1988;65:309-17.

37. Wrigge H, Golisch W, Zinserling J, Sydow M, Almeling G, Burchardi H. Proportional assist versus pressure support ventilation: effects on breathing pattern and respiratory work of patients with chronic obstructive pulmonary disease. Intensive Care Med 1999;25:790-8. 